\title{
Formation of Projection Pathways from the Arcuate Nucleus of the Hypothalamus to Hypothalamic Regions Implicated in the Neural Control of Feeding Behavior in Mice
}

\author{
Sebastien G. Bouret, Shin J. Draper, and Richard B. Simerly \\ Division of Neuroscience, Oregon National Primate Research Center, Oregon Health and Science University, Beaverton, Oregon 97006
}

\begin{abstract}
The arcuate nucleus of the hypothalamus (ARH) is a critical component of forebrain pathways that regulate a variety of neuroendocrine functions, including an important role in relaying leptin signals to other parts of the hypothalamus. However, neonatal rodents do not lose weight in response to leptin treatment in the same way as do adults, suggesting that certain aspects of leptin signaling pathways in the hypothalamus may not be mature. We tested this possibility by using DiI axonal labeling to examine the development of projections from the ARH to other parts of the hypothalamus in neonatal mice, paying particular attention to the innervation of the paraventricular nucleus (PVH), the dorsomedial nucleus (DMH), and the lateral hypothalamic area (LHA), each of which have been implicated in the regulation of feeding. The results indicate that ARH projections are quite immature at birth and appear to innervate the DMH, $\mathrm{PVH}$, and LHA in succession, within distinct temporal domains. The projections from the ARH to the DMH develop rapidly and are established by the sixth postnatal day (P6), whereas those to the PVH develop significantly later, with the mature pattern of innervation first apparent between postnatal day 8 (P8)-P10. Furthermore, the ability of leptin to activate Fos in the PVH, DMH, and LHA appears to be agedependent and correlates with the arrival of ARH projections to each nucleus. Taken together, these findings provide new insight into development of hypothalamic circuits and suggest an anatomical basis for the delayed postnatal regulation of food intake and body weight by leptin.
\end{abstract}

Key words: arcuate; axon; development; feeding; hypothalamus; neuroendocrine; projection; leptin; cFos; POMC; NPY; obesity

\section{Introduction}

The arcuate nucleus of the hypothalamus (ARH) plays a central role in a variety of homeostatic circuits and is a particularly important site for the central regulation of food intake, energy expenditure, and body weight. Systemic administration of the neurotoxic glucose analog, gold thioglucose, or treatment of neonatal rats with high doses of monosodium glutamate, result in severe neuronal loss in the ARH and are linked to obesity syndromes characterized by increased food intake (Debons et al., 1982; Meister et al., 1989; Bergen et al., 1998). The ARH is a key site for the integration of peripheral signals with other sensory information and is known to relay leptin signals to other parts of the hypothalamus. Leptin, which is derived from adipocytes, acts to inhibit food intake and stimulates catabolic, autonomic, and neuroendocrine responses that tend to direct nutrient stores away from the fat compartment (Woods et al., 1998). Leptin receptors are expressed in the ARH (Elmquist et al., 1998a) and it contains high densities of neurons that express Fos protein and SOCS-3 mRNA after intravenous injection of leptin (Elias et al.,

Received Dec. 4, 2003; revised Jan. 23, 2004; accepted Jan. 26, 2004.

This work was supported by National Institutes of Health Grants NS37952, DK65900, and DK055819.

Correspondence should be addressed to Richard B. Simerly, Neuroscience, Oregon National Primate Research Center, Oregon Health and Science University, 505 Northwest 1 Eighty-Fifth Avenue, Beaverton, OR 97006. E-mail: bourets@ohsu.edu.

DOI:10.1523/JNEUROSCI.5369-03.2004

Copyright $\odot 2004$ Society for Neuroscience $\quad$ 0270-6474/04/242797-09\$15.00/0
1998, 1999, 2000; Elmquist et al., 1998b). Lesions of the ARH result in leptin insensitivity (Choi et al., 1999), and viral transfection of leptin receptor into ARH neurons alone is sufficient to cause reductions in food intake in leptin receptor-deficient rats (Morton et al., 2003). From the ARH, leptin signals appear to be distributed through neural projections to other sites implicated in the control of feeding, such as the paraventricular nucleus of the hypothalamus (PVH), the dorsomedial hypothalamic nucleus (DMH), and the lateral hypothalamic area (LHA) (Elias et al., 1998, 1999; Elmquist et al., 1998b).

Despite widespread appreciation for the importance of ARH projections in body weight regulation, very little is known about the development of these critical pathways. However, physiological differences in the regulation of energy balance between adult and neonatal rodents suggest that certain aspects of the hypothalamic circuits regulating feeding may not be mature early in life. For instance, exogenous leptin treatment normally causes a sharp decline in feeding, but does not affect body weight, food intake, or metabolic rate during the first two postnatal weeks (Mistry et al., 1999; Proulx et al., 2002). Moreover, Zucker fatty ( $f a / f a$ ) rats lack functional leptin receptors, but the hyperphagia characterizing these animals develops only on postnatal day 12 (P12) (Kowalski et al., 1998, 1999). Thus, it is possible that the regulatory actions of leptin require formation of ARH projections before the leptin signals can be distributed to parts of the hypothalamus that mediate feeding. 
The present study used axonal labeling to define the ontogeny of ARH projections, paying particular attention to the innervation of the DMH, PVH, and LHA, which represent nodal points in neural pathways that regulate feeding behavior. In addition, we examined formation of projections from the $\mathrm{DMH}$ to the $\mathrm{PVH}$, because this pathway has also been implicated in food intake and body weight regulation (Elmquist et al., 1999; Thompson and Swanson, 2003). The results indicate that $\mathrm{ARH}$ projections through the hypothalamus are formed primarily during the second week of life and innervate the PVH, DMH, and LHA at unique time points. Moreover, the pattern of neurons that display changes in cFos expression in response to acute leptin treatment at distinct postnatal ages reflected this developmental pattern and suggest that these developmental events are essential for expression of mature patterns of homeostatic regulation of feeding.

A portion of these results has been presented in abstract form (Bouret et al., 2001).

\section{Materials and Methods}

DiI implants in postnatal mice. A total of 107 neonatal male and female C57BL/6 mice (Taconic, Germantown, NY) were anesthetized with tribromoethanol and perfused on P4, P6, P8, P10, P12, P14, P16, P18, and $\mathrm{P} 21$ with a 4\% paraformaldehyde solution, $\mathrm{pH}$ 7.4. The protocols used for the studies were approved by the Oregon Health and Sciences University Committee for the Care and Use of Animals in Research and Education, in accordance with the guidelines of the National Institutes of Health and United States Department of Agriculture. The brains were removed immediately from each perfused animal and stored in fixative at $4^{\circ} \mathrm{C}$ until further processing. In preparation for labeling, the brains were blocked, embedded in 3\% agarose, and sectioned from caudal to rostral to expose the ARH without disturbing rostral regions. Each brain block was stained with methylene blue to visualize morphological features of the exposed surface of the block, which allowed unambiguous identification of the morphological borders of the ARH. An insect pin was used to place a small crystal $(\sim 20-40 \mu \mathrm{m}$ in diameter $)$ of DiI $\left(1,1^{\prime}-\right.$ dioctadecyl-3,3,3',3' -tetramethylindocarbocyanine perchlorate; Molecular Probes, Eugene, OR) into the ARH of each brain under visual guidance with the assistance of a stereo-zoom microscope. For comparison, several brains, collected from mice on P6, received DiI implants into the DMH. After implantation, the brain blocks were stored in $4 \%$ paraformaldehyde, and the DiI was allowed to diffuse for 6 weeks in the dark at $37^{\circ} \mathrm{C}$. Then, $80-\mu \mathrm{m}$-thick sections through the hypothalamus were cut on a vibratome, mounted onto poly-L-lysine-coated glass slides, and coverslipped with $65 \%$ buffered glycerol.

Analysis. Sections were evaluated with both conventional fluorescence and confocal microscopy. The overall distribution of DiI-labeled fibers was first evaluated by viewing sections with a Zeiss Axioplan2 epifluorescence microscope equipped with optics optimized for visualization of DiI fluorescence. A series of $20-\mu \mathrm{m}$-thick sections through the hypothalamus of a P10 mouse was used as a standard reference Nissl series. To prepare the images presented in the photographic figures, eight images were collected at $2 \mu \mathrm{m}$ intervals through an $80-\mu \mathrm{m}$-thick section by using a $10 \times$ water-corrected objective (numerical aperture, 0.40 ).

Quantitative analysis. Confocal images of DiI-labeled fibers were collected through the hypothalamus of P6, P8, P10, P12, P14, and P16 mice by using a Leica (Heidelberg, Germany) TCS SP confocal microscope. The following regions were analyzed within each tissue section: (1) the $\mathrm{DMH},(2)$ the LHA at the level of the DMH, (3) the medial parvicellular component of the $\mathrm{PVH}$, and (4) the posterior magnocellular component of the PVH. The morphological limits of each nucleus were easily recognized in the SYTOX green (Molecular Probes) counterstained sections. For this purpose, an electronically digitized square of constant dimensions $(200 \times 200 \mu \mathrm{m}$ for the PVH; $400 \times 400 \mu \mathrm{m}$ for the $\mathrm{DMH}$ and the LHA) was centered over each region examined. For quantification, a series of 10 adjacent optical sections were collected by using a $10 \times$ objective [numerical aperture, 0.40 ; working distance, $360 \mu \mathrm{m}$ ] and a $1 \mu \mathrm{m}$ $z$-axis interval. Image analysis was performed by using Metamorph image analysis software (Universal Imaging Corporation, West Chester, PA). Maximum intensity projections were prepared for each series of confocal images and then binarized according to user-defined threshold parameters that optimized detection of labeled fibers. The total number of pixels in each binarized image was counted and used as an index of the overall density of labeled fibers in each nucleus examined.

cFos immunostaining and analysis. Age-matched groups of mice received intraperitoneal injections of recombinant mouse leptin $(10 \mu \mathrm{g} /$ gm; R \& D Systems, Minneapolis, $\mathrm{MN}$ ) dissolved in $10 \mathrm{~mm}$ Tris- $\mathrm{HCl}, \mathrm{pH}$ $7.4(n=3$ per age), or buffer alone $(n=3$ per age $)$ on P6, P10, and P16. At 90 or $120 \mathrm{~min}$ after leptin or vehicle administration, mice were anesthetized with tribromoethanol and perfused transcadially with a $4 \%$ paraformaldehyde solution, $\mathrm{pH}$ 9.5. Frozen coronal sections were cut at $20 \mu \mathrm{m}$ using a cryostat microtome and then processed for immunofluorescence as described elsewhere (Gu et al., 2001). After pretreatment overnight in a mixture of $0.3 \%$ Triton $\mathrm{X}-100$ and $2 \%$ normal goat serum, sections were incubated for $48 \mathrm{hr}$ at $4^{\circ} \mathrm{C}$ in a rabbit primary antiserum directed against the N-terminal domain of Fos. There is no known crossreaction between this antibody and any identified Fos-related genes (Ab-5; 1:2000; Oncogene Sciences, Uniondale, NY) (Elmquist et al., 1998b). The primary antibodies were localized with affinity-purified IgGs conjugated with Alexa 488 (1:200; Molecular Probes). Sections were counterstained using bis-benzamide $(1: 10,000)$ to visualize cell nuclei and coverslipped with buffered glycerol, $\mathrm{pH}$ 8.5. To confirm that cFos is induced in proopiomelanocortin (POMC) neurons, double immunofluorescence staining was performed on an additional series of sections through the arcuate nucleus. Briefly, the sections were incubated in a mixture of sheep antiserum directed against the POMC-derived peptide $\alpha$-MSH (1:20,000; Chemicon, Temecula, CA), and an antiserum for cFos raised in rabbits (1:2000; Oncogene). The primary antibodies were localized with affinity-purified secondary antibodies: donkey anti-sheep IgG Alexa 568 and donkey anti-rabbit IgG Alexa 488, respectively. Slides were numerically coded to obscure the treatment group; cFosimmunopositive cells were counted manually by using a Zeiss Axioplan 2 microscope and a $10 \times$ objective. Immunoreactive cells were counted in each section of a 1-in-3 (1 section every $60 \mu \mathrm{m})$ series of $20-\mu \mathrm{m}$-thick sections through the ARH, LHA, DMH, and PVH. The mean number of immunopositive cells in each nucleus was compared between ages by using ANOVA. For illustration purposes, images from selected sections were captured using a Leica TSCSP confocal microscope and then processed for size and contrast by using Photoshop (Adobe Systems, San Jose, CA).

\section{Results}

Discrete injection sites were obtained in 62 cases in which crystalline deposits of DiI were primarily confined to the ARH (P4 mice, $n=5 ; \mathrm{P} 6, n=8 ; \mathrm{P} 8, n=7 ; \mathrm{P} 10, n=7 ; \mathrm{P} 12, n=10 ; \mathrm{P} 14, n=$ 9; $\mathrm{P} 16, n=8 ; \mathrm{P} 18, n=8$; and $\mathrm{P} 21, n=4)$. In these cases, analysis of the implantation sites showed that the DiI extended throughout the ARH without significant spreading of the tracer into adjacent areas, although there were often a few isolated DiI-labeled neurons along the margin of the ARH (Fig. 1). Successful implants were centered at various levels in the ARH, and in more rostral placements the dye extended into the caudal part of the retrochiasmatic area. In addition, other cases were analyzed in which the dye was placed into adjacent structures, such as the ventromedial hypothalamic nucleus, which revealed a markedly different pattern of labeled fibers compared with that seen in brains with DiI implants in the ARH.

In all cases the majority of labeled fibers originating from injection sites in the ARH were confined to the periventricular zone of the hypothalamus, which appears to be the major route for ascending ARH efferent connections (see Swanson, 1992 for a description of hypothalamic parcelation). Another striking feature was that both the distribution pattern and the timing of ARH projections were virtually identical in males and females. There- 

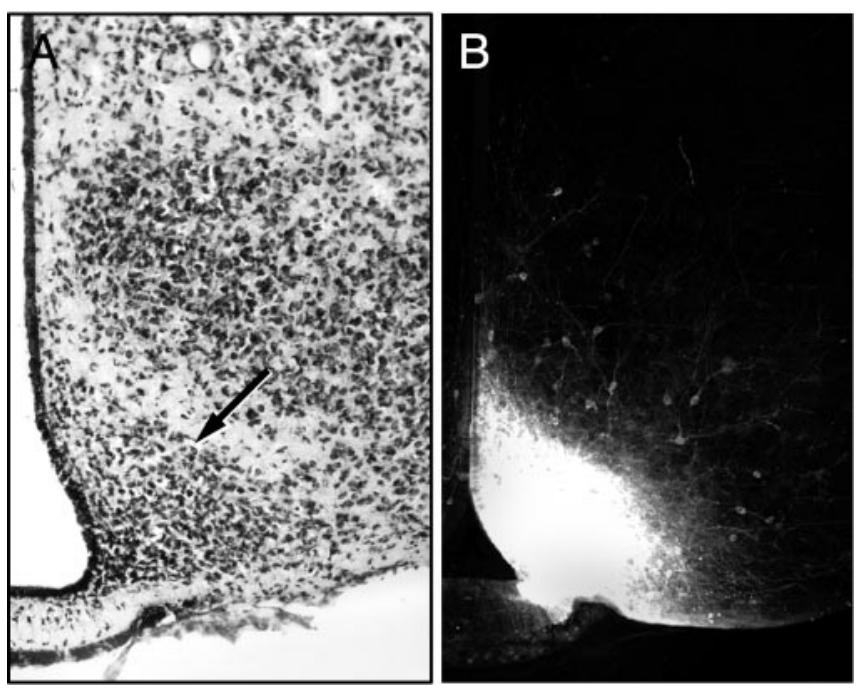

Figure 1. A, Low magnification images of a Nissl-stained section showing a representative Dil implant in the ARH of a P10 mouse. The arrow indicates the location of the lateral margin of the ARH. $B$, Low magnification confocal image showing the appearance and distribution of Dil in a P10 mouse.

is summarized below. By P18, neurons in the ARH appear to innervate each of the periventricular nuclei of the hypothalamus, but provide the strongest inputs to the $\mathrm{DMH}$, the $\mathrm{PVH}$, the medial preoptic nucleus (MPN), and the anteroventral periventricular nucleus (AVPV). From the cells of origin, labeled axons pass rostrally through the periventricular zone and provide numerous terminations as the fibers ascend along this pathway. The DMH contained a dense plexus of DiI-labeled fibers, and the highest density of fibers was localized to its anterior and posterior parts. Although the majority of axons to the DMH appear to end in its anterior and posterior parts, the ventral part of the DMH also appears to receive a moderate density of inputs from the ARH. Other ARH projection fibers pass dorsally through the periventricular zone, arch laterally along the dorsal border of the $\mathrm{DMH}$, and appear to end in the LHA. At more rostral levels the PVH contained a particularly dense plexus of labeled fibers in parvocellular components. In contrast, the magnocellular parts of the $\mathrm{PVH}$ appear to receive considerably fewer inputs from the ARH, although a moderate number of labeled fibers pass laterally from the periventricular zone through the dorsal parvicellular part of the PVH to end in the lateral zone of the posterior magnocellular part of the nucleus. Although neurochemical studies suggest that the anatomical or-
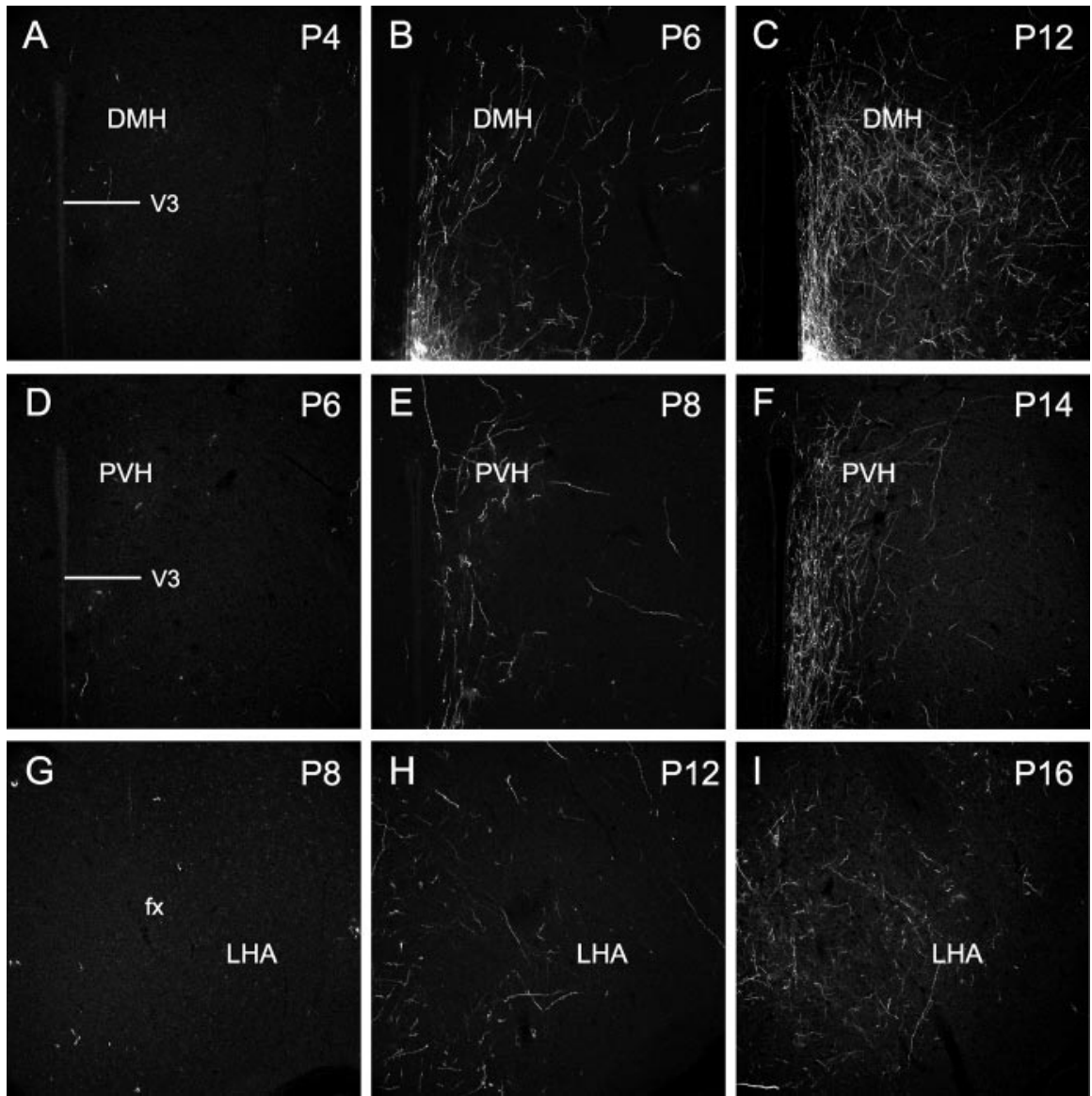

Figure 2. Confocal images of arcuate Dil-labeled fibers in the DMH $(A-C)$, PVH $(D-F)$, and LHA $(G-I)$ of mice on P4 $(A), P 6(B$, $D), P 8(E, G), P 12(C, H), P 14(F)$, and P16 (I). A maximal projection image was derived from eight confocal images collected (10X objective) through a total distance of $16 \mu \mathrm{m}$ in an $80-\mu \mathrm{m}$-thick section. fx, Fornix; V3, third ventricle.

fore, the following descriptions apply to both sexes. By P18, the pattern of projections from the ARH resembled that of adult mice or rats (Qiu et al., 2001), and because a detailed account has not been published, the distribution of DiI-labeled fibers in P18 mice ganization of the PVH in mice is similar to that of rats (Swanson, 1987), relatively little is known about the detailed organization of projections from the PVH in the mouse.

At the level of the $\mathrm{PVH}$, the anterior hypothalamic nucleus contained a moderate density of labeled fibers, and a few fibers appeared to extend dorsally through the nucleus reunions and end in the periventricular nucleus of the thalamus. A dense bundle of labeled fibers also extend rostral through the preoptic part of periventricular nucleus of the hypothalamus, and some of these extend into the MPN. Most of these labeled fibers appear to end in a dense plexus of fibers and terminals in the medial and central parts of the MPN; the lateral part contained a more sparse distribution of labeled fibers. The majority of the remaining labeled fibers in the periventricular pathway appear to end in the AVPV, but a significant number pass dorsally to end in the principal nucleus of the bed nuclei of the stria terminalis and in the ventral part of the lateral septal nucleus.

\section{Development of ARH projections to the DMH}

The DMH appears to be the first major hypothalamic nucleus to receive inputs from the ARH. In P4 animals, labeled fibers are located in the periventricular pathway, but very few extend into the DMH (Fig. 2A). Labeled fibers from the ARH first reach the DMH on P6 with a low to moderate density of fibers present in the anterior and posterior parts of the $\mathrm{DMH}$ (Figs. $2 B, 3 A$ ); the ventral part of the DMH was virtually devoid of labeled fibers. By P12, the distribution pattern of labeled fibers 
from the ARH in the $\mathrm{DMH}$ appeared similar to that of $\mathrm{P} 16$ mice (Figs. 2C, 3A). At P12 both the anterior and posterior parts of the $\mathrm{DMH}$ contained a high density of labeled fibers, but only a moderate number of fibers were present in the ventral part of the nucleus. Semiquantitative analysis of confocal images through the $\mathrm{DMH}$ revealed that fiber density in the $\mathrm{DMH}$ increased by approximately sixfold to sevenfold between P6 and P12 mice (Fig. 3A).

\section{Development of ARH projections to the LHA}

In contrast to other arcuate terminal fields, the LHA receives afferents from the ARH via two distinct routes: one that includes fibers that pass through the DMH from the periventricular pathway, and a ventral route that passes ventral and lateral to the ventromedial hypothalamic nucleus. Although projections from the $\mathrm{ARH}$ to the $\mathrm{DMH}$ develop as early as $\mathrm{P} 6$, the projections to the LHA appear to reach their target much later during postnatal development (Figs. 2, 3). On P6 or P8, no fibers arising from the ARH reach the LHA (Fig. 2G). Rarely were labeled fibers observed the LHA of mice perfused on P10, but by P12 the innervation of the LHA by the ARH was evident (Fig. $2 \mathrm{H}$ ). The majority of fibers innervating the LHA appear to originate from the ventral pathway. A mature pattern of projections from the ARH to the LHA was not observed until P16 (Fig. 2I). Analysis of fiber density in the LHA revealed an $\sim 15$-fold increase between P9 and P16 mice (Fig. 3B).

\section{Development of ARH projections to the PVH}

Labeled fibers projecting from the ARH into the PVH were sparse before P8 (Fig. 2D). In mice perfused on P8, labeled fibers extended rostrally through the periventricular pathway, but few of these reached the parvicellular parts of the PVH (Fig. 2E). The magnocellular part of the nucleus was nearly devoid of labeled fibers at this age. In P10 animals, the pathway from the ARH to the PVH was clearly evident with a dense plexus of labeled fibers located in the anterior parvicellular part of the nucleus and in the dorsal zone of its medial parvicellular part (Fig. 3C,D). Although the dorsal parvicellular part of the PVH contained a moderate density of labeled fibers, other parts of the PVH contained only a few DiI-labeled fibers. In addition, the lateral parvicellular part of

A
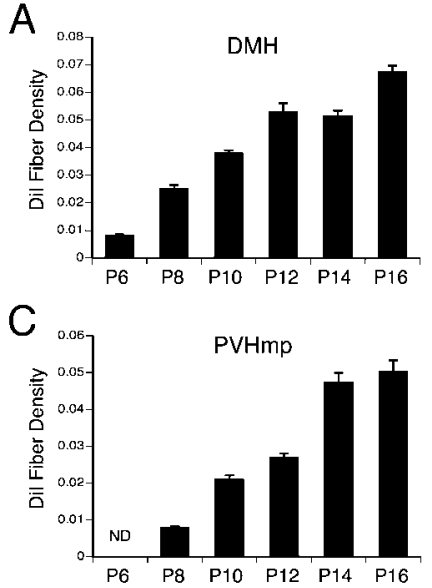

Figure 3. Quantitative comparison of Dil-labeled fibers within the DMH $(A), \operatorname{LHA}(B)$, parvicellular ( $C$, and magnocellular $(D)$ components of the PVH in mice at different stages of postnatal development. Bars depicts the mean of the total numbers if pixels in user-defined regions of thresholded, binarized images of Dil-labeled fibers, derived from a maximum projection images of 10 confocal image planes and collected with a $10 \times$ objective from three animals with comparable Dil implants centered in the ARH. ND, Not detectable. the PVH is completely devoid of ARH fibers at P10. Not until P14 was the distribution of labeled fibers in the PVH comparable to that of P18 mice (Fig. 2 F). Analysis of confocal images revealed a more than sixfold increase in the density of labeled fibers in the parvicellular components of the PVH between P8 and P14 mice (Fig. 3C). At every age examined, the density of labeled fibers was significantly higher in the parvicellular, as compared with magnocellular, components of the PVH (Fig. 3C,D).

\section{Development of ARH projections to the preoptic region}

Ascending projections from the ARH to the preoptic area appear to be the last to reach their hypothalamic targets. In P12 animals, a few labeled fibers from the periventricular pathway extended into both the medial and central parts of the MPN, but did not appear to enter other parts of the medial preoptic area. By P14, the mature pattern of projections from the ARH to the MPN was observed (Fig. 4A,B), and a few labeled fibers reach the AVPV (Fig. 4C,D). In addition, a few labeled fibers from the ARH pass dorsally through the periventricular zone and end in the median preoptic nucleus. The projections from the ARH to the AVPV developed rapidly and appeared to achieve their mature distribution by $\mathrm{P} 18$.

\section{Development of ARH projections to extrahypothalamic regions}

Projections from the ARH to extrahypothalamic regions develop late during the neonatal period. ARH fibers start to innervate the BSTp at P12, and the distribution of labeled fibers does not appear to change significantly after P14. Rostrally, at the level of the AVPV, labeled fibers extended into the anteroventral and the dorsomedial nucleus of the anterior divisions of the BST at P14 and increased in density through P18 (Fig. 4E,F). Also, the first appearance of labeled fibers from the ARH to the paraventricular nucleus of the thalamus, or ventral part of the lateral septum, occurred by P14, and these pathways also appeared to be fully developed by P18 (Fig. 4G,H).

\section{Control injections}

DiI implants placed rostral, caudal, or ventral to the ARH produced labeling patterns that were distinct from those resulting from implants centered in the nucleus. We obtained several cases with DiI implants centered in regions adjacent to the ARH of P10 mice. Our collection of such cases is not extensive enough to allow for a detailed description of the projections of cells located in cell groups surrounding the ARH. However, the results of these experiments merit comment because they serve as control cases and support the specificity of the distribution patterns of ARH projections in neonatal mice, as well as confirming our interpretation of the effective limits of injections centered in the ARH.

Four implants were centered in the ventromedial nucleus of the hypothalamus (VMH) of P10 mice, and the pattern of projections was quite different from that described above for the $\mathrm{ARH}$. In contrast to ARH projections, implants of DiI into the VMH resulted in a high density of labeled fibers in the medial zone of the hypothalamus, although a low to moderate number of labeled axons course through the periventricular zone of the hypothalamus as well. Moreover, in these P10 brains labeled fibers pass through the medial zone and appear to supply strong inputs to the LHA and the anterior hypothalamic nucleus, whereas, at this age, these regions were almost devoid of fibers derived from the ARH. The VMH also appears to send only minor inputs to the anterior part of the $\mathrm{DMH}$, which receives a massive input from the $\mathrm{ARH}$ by $\mathrm{P} 10$. In contrast, the pattern of projections from the 

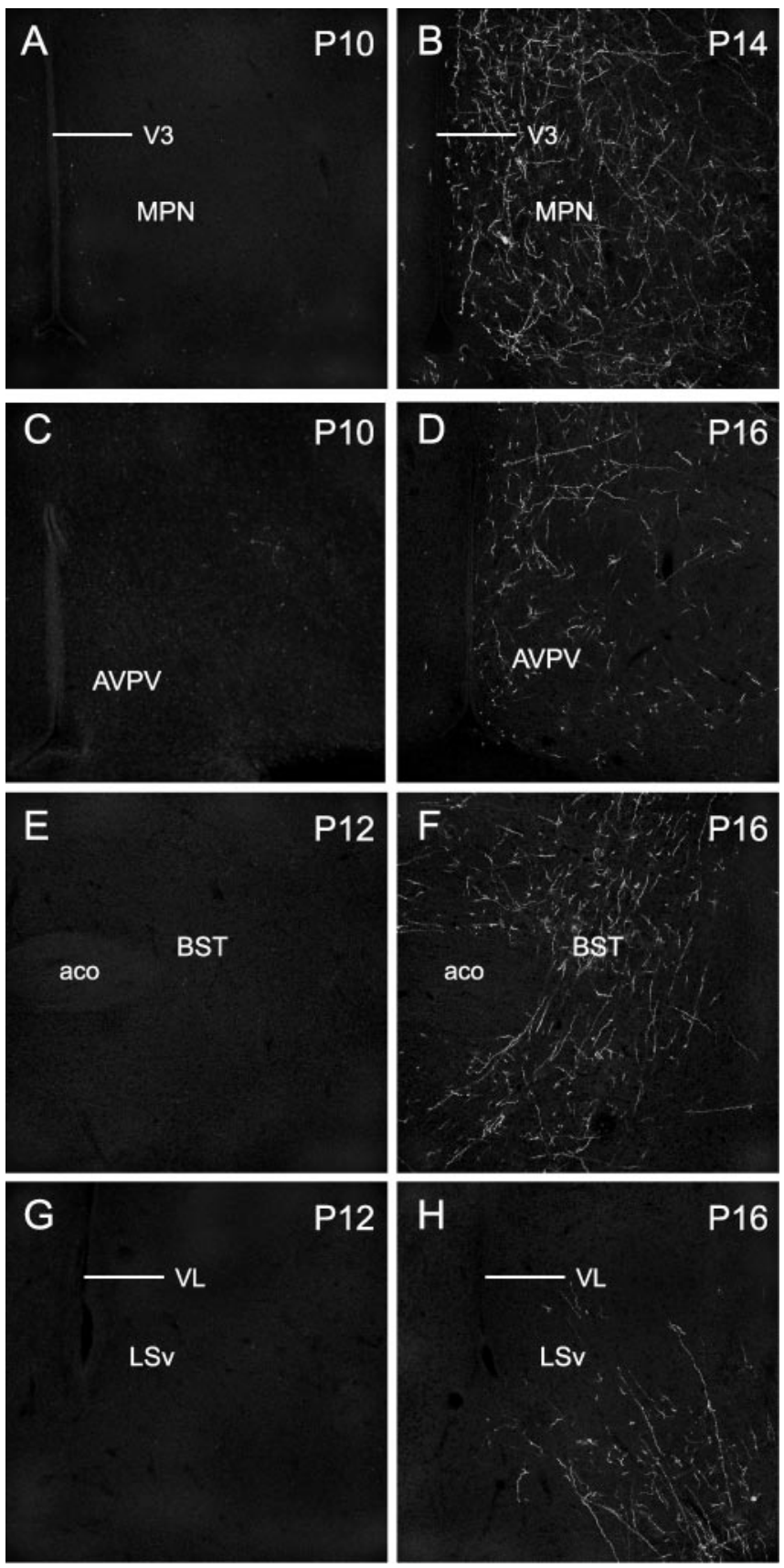

Figure 4. Confocal images of arcuate Dil-labeled fibers in the MPN $(A, B), \operatorname{AVPV}(C, D), B S T$ $(E, F)$, and $L S v(G, H)$ of $P 10(A, C), P 12(E, G), P 14(B)$, and $P 16(D, F, H)$ mice. A maximal projection image was derived from eight confocal images collected ( $10 \times$ objective) through a total distance of $16 \mu \mathrm{m}$ in an 80- $\mu \mathrm{m}$-thick section. aco, Anterior commissures; BST, bed nuclei of the stria terminalis; LSv, ventral part of the lateral septal nucleus; MPN, median preoptic nucleus; V3, third ventricle; VL, lateral ventricle.

VMH to the PVH resembles that of ARH fibers, including strong inputs to the parvicellular parts of this nucleus. In addition, it should be noted that only a few labeled fibers were found in the $\mathrm{ARH}$ itself in control cases, suggesting that ARH neurons do not receive inputs from the surrounding region.

\section{Projection pathways from the DMH on $\mathrm{P} 6$}

Although projections from the ARH to the PVH are immature at $\mathrm{P} 6$, they appear to innervate the $\mathrm{DMH}$ by this age, and the $\mathrm{DMH}$ also represents an important component of hypothalamic pathways that mediate leptin signals (Elmquist et al., 1998). Therefore, we investigated whether projections from the DMH to the PVH were established by P6 because such a pathway would provide an alternative route for leptin signals before projections from the $\mathrm{ARH}$ to the $\mathrm{PVH}$ mature. In five brains derived from mice on P6, injections were centered in the DMH (Fig. 5A, B). In these brains DiI-labeled fibers extended rostrally through the periventricular zone of the hypothalamus and appear to provide substantial inputs to the PVH and the LHA (Fig. 5C,D). Within the $\mathrm{PVH}$, fibers and terminals arising from the $\mathrm{DMH}$ are distributed primarily in parvicellular parts of the nucleus; magnocellular parts of the PVH contained relatively few labeled fibers. In addition to the periventricularly projecting fibers, a second group of labeled axons extends laterally from the DMH and ends in a relatively dense plexus of labeled fibers in the perifornical region of the LHA. In contrast to the adult pattern of DMH projections (Thompson et al., 1996), the suprachiasmatic and median preoptic nuclei contained only a few fibers on P6, and rarely were labeled fibers observed in the ARH at this age.

\section{Postnatal development of cFos-IR induced by leptin}

To determine if the ability of leptin to induce changes in cFos expression in ARH targets correlates with the ontogeny of $\mathrm{ARH}$ projections, we evaluated the distribution and density of cFosimmunoreactive neurons in the ARH, LHA, and PVH of mice on P6, P10, and P16 at 90 or 120 min after injection with leptin, or vehicle alone. Vehicle-injected animals had only a low density of cFos-immunoreactive cells in each nucleus and displayed no significant variations across the ages studied (see Fig. 7). In contrast, leptin treatment caused marked increases in cFos staining in the $\mathrm{ARH}$ at each age examined. Clear differences in cFos induction were observed in each target region that correlated with the temporal organization of innervation by the ARH. On P6, leptin administration induced cFos-IR in the ARH, whereas very few cFos-IR neurons were found in the PVH and LHA of leptintreated mice at this age (Figs. 6, 7). On P10, the number of cFos-IR cells in the ARH was comparable to that found on P6, but there was a fourfold induction in cFos immunoreactivity in the PVH in leptin-treated mice at P10 (Fig. 7). However, leptin treatment caused only a small increase in the number of cFos-IR nuclei in the LHA of P10 mice, presumably because only a few $\mathrm{ARH}$ axons have reached the LHA by this age. By $\mathrm{P} 16$, projections from the ARH to the PVH and LHA are well developed, and leptin treatment caused a sharp induction in cFos-IR in each region (Figs. 6, 7). In the DMH, leptin treatment caused a moderate increase in cFos staining on P6 and a marked induction of cFos-IR on P10 and P16 (data not shown).

Finally, to determine whether leptin activates POMC neurons in the ARH during postnatal life, as it does in adults (Elias et al., 1999), we performed dual-labeling experiments using antisera to Fos and $\alpha$-melanocyte stimulating hormone ( $\alpha$-MSH), a POMCderived anorexic peptide. At each age analyzed (P6, P10, and $\mathrm{P} 16)$, leptin significantly induced Fos-IR in a substantial number of $\alpha$-MSH-immunoreactive ( $\alpha$-MSH-IR) neurons throughout the ARH (average coexpression, leptin 21\%, control 2\%) (Fig. 8).

\section{Discussion}

The primarily intrahypothalamic projections of the ARH are consistent with its role as a key component of neuroendocrine circuitry. In addition to containing neuroendocrine neurons that regulate hormone release from the anterior pituitary gland directly through innervation of portal vessels in the median emi- 

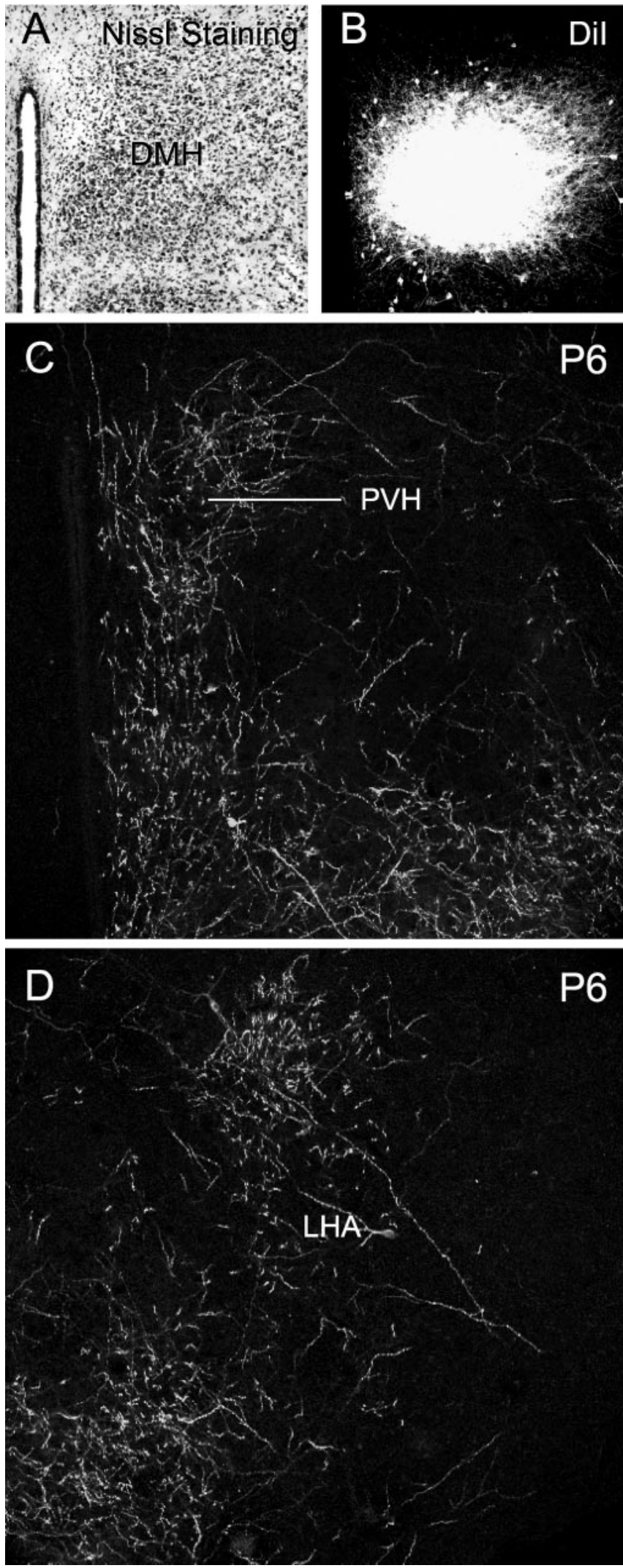

Figure 5. A, Low magnification images of a Nissl-stained section showing a representative Dil implant in the DMH of a P6 mouse. $B$, Low magnification confocal image showing the appearance and distribution of Dil in a $\mathrm{P} 6$ mouse. $C, D$, Confocal images of Dil-labeled fibers in the PVH ( $C$ and LHA $(D)$ after Dil placement in the DMH of P6 mice $(A, B)$. A maximal projection image was derived from eight confocal images collected (10× objective) through a total distance of $16 \mu \mathrm{m}$ in an $80-\mu \mathrm{m}$-thick section.
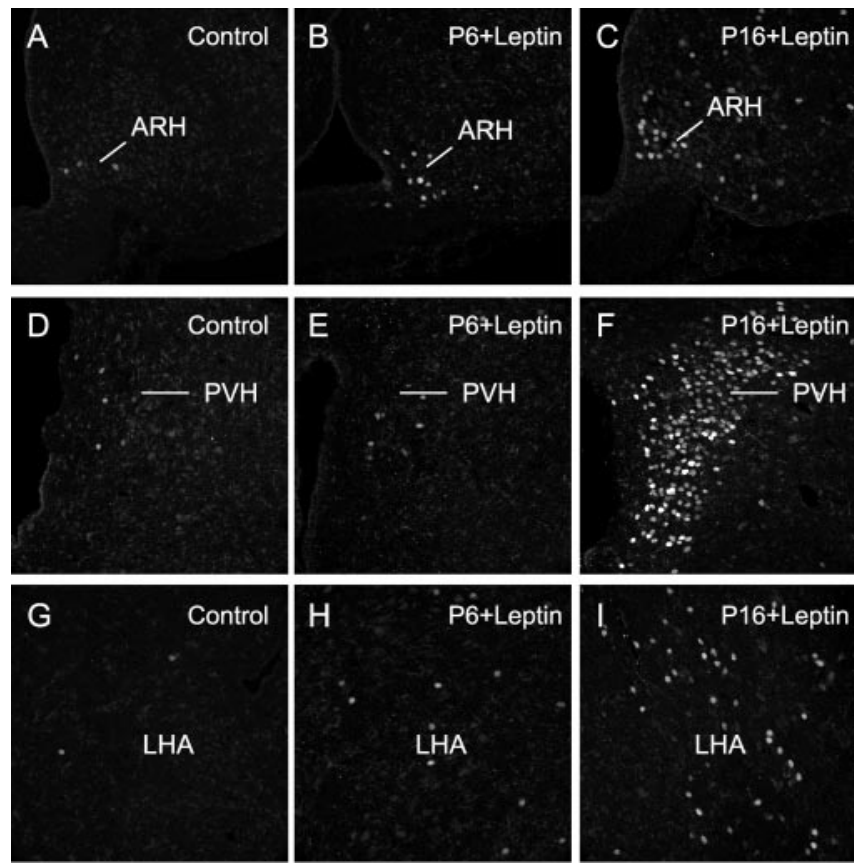

Figure 6. Confocal images illustrating the expression of Fos-immunoreactivity (Fos-IR) in the ARH ( $A-C)$, PVH ( $D-F)$, and LHA ( $G-I) 90 \mathrm{~min}(A-C, G-I)$ or $120 \mathrm{~min}(D-F)$ after intraperitoneal administration of leptin $(10 \mathrm{mg} / \mathrm{kg})$ on $\mathrm{P} 6(B, E, H)$ or $P 16(C, F, I)$ mice. $A, D$, and $G$ show typical Fos-IR in mice injected with vehicle (here on P10). A maximal projection image was derived from 10 confocal images collected ( $25 \times$ objective) through a total distance of $20 \mu \mathrm{m}$.
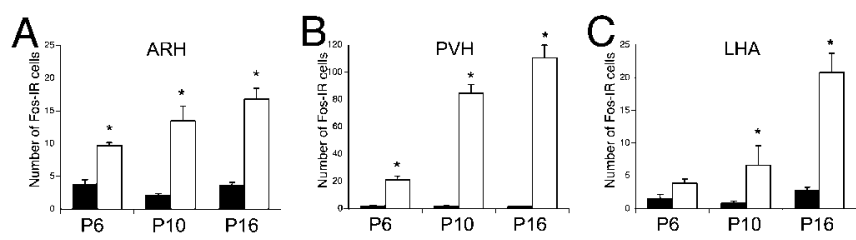

Figure 7. Number of Fos-IR cells in the ARH $(A)$, PVH $(B)$, and LHA ( $C$ ) of mice that were administrated intraperitoneally with $10 \mathrm{mg} / \mathrm{kg}$ of leptin (white bars) or vehicle (black bars) on P6, P10, or P16. Values are the mean \pm SEM $(n=3)$. Differences between groups were determined by ANOVA. ${ }^{*} p<0.05$ compared with vehicle-treated mice.

nence, neurons in the ARH provide inputs to nearly the entire periventricular zone of the hypothalamus (Sawchenko and Swanson, 1983; Simerly, 1998; Qiu et al., 2001). The present study represents the first systematic examination of the development of neural projections from any hypothalamic nucleus. Previous work has established patterns of neurogenesis in the hypothalamus (for review, see Markakis, 2002) and documented neuronal migration and differentiation (for review, see Markakis, 2002; Tobet, 2002). Neurons in the ARH are generated from the ventral part of the periventricular neuroepithelium between embryonic day 12 (E12) and E17 (for review, see Markakis, 2002), with POMC and NPY neurons appearing as early as E12 (Khachaturian et al., 1985) and E15 (Kagotani et al., 1989), respectively. In addition, numerous studies have examined how sex steroid hormones influence patterns of development in sexually dimorphic nuclei, many of which reside in the hypothalamus (for review, see Madeira and Lieberman, 1995; Tobet and Hanna, 1997; de Vries and Simerly, 2002; Simerly, 2002). However, we know relatively little about how and when patterns of hypothalamic connectivity are established. By applying the widely used tracer DiI to label $\mathrm{ARH}$ axons in mice at various postnatal ages, we succeeded in visualizing the ontogeny of ARH projections. Our results indicate 

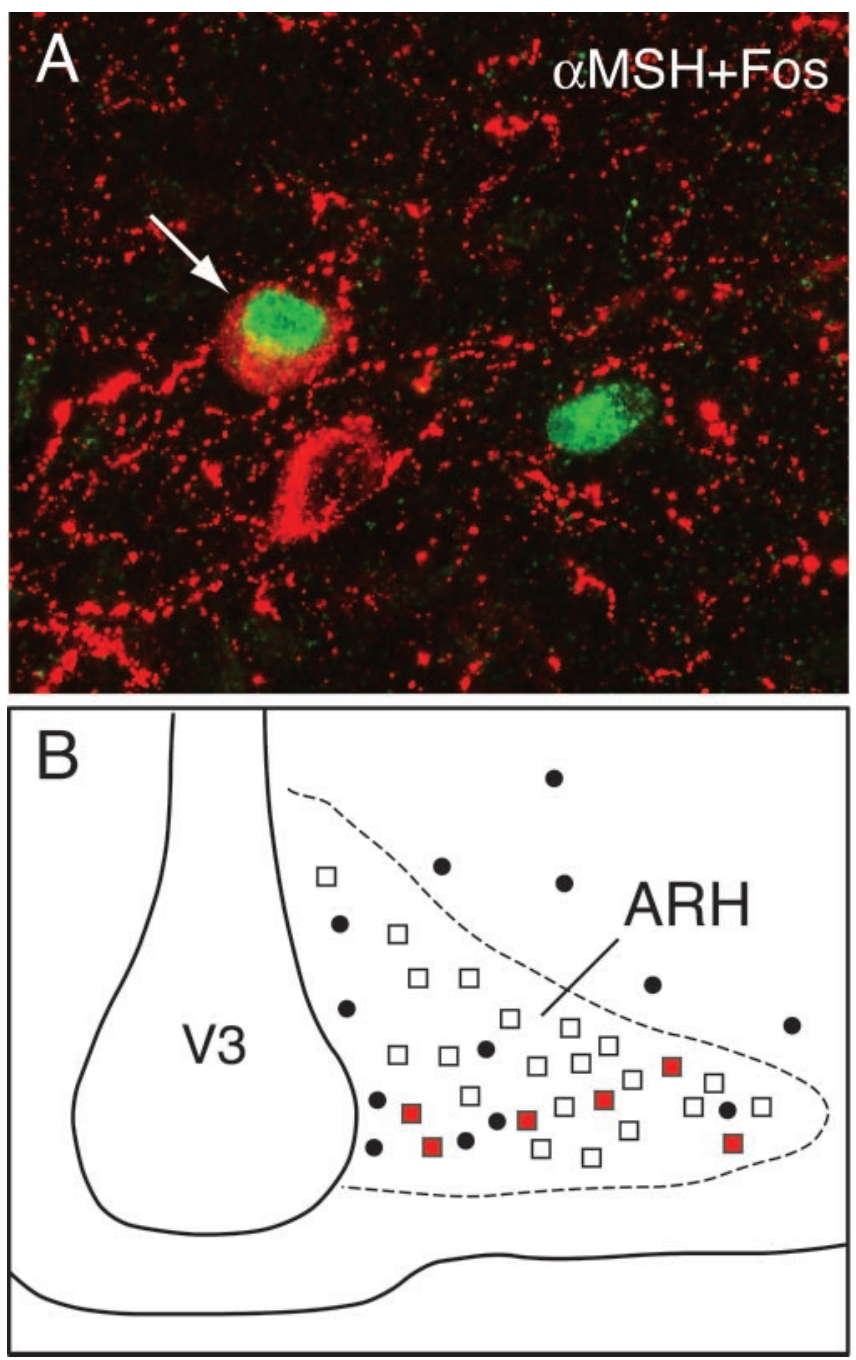

Figure 8. Leptin activates POMC neurons during the postnatal life. A, Representative confocal image showing induction of Fos-IR (green fluorescence) in arcuate neurons containing $\alpha$-melanocyte stimulating hormone ( $\alpha$-MSH, red fluorescence; arrows) of a P10 mouse $90 \mathrm{~min}$ after leptin administration. $B$, Line drawing of a representative section through the ARH to illustrate the distribution of leptin-induced Fos-IR in POMC neurons (red squares). Cells containing only POMC (empty squares) or Fos (circles) are also represented.

that ARH projections extend through the periventricular zone of the hypothalamus to provide inputs to the DMH first (on P6), followed by inputs to the PVH (on P10) and then to the LHA (on $\mathrm{P} 12$ ). Rostral projections from the ARH to the preoptic region, as well as projections to extrahypothalamic nuclei, reach their targets much later during postnatal development. Not until P18 did the pattern of ARH projections display a distribution pattern that resembled that of adult mice. These observations have clear implications for homeostatic mechanisms during postnatal development. For example, neurons in the ARH play an essential role in regulating secretion of $\mathrm{LH}$ (Gerall and Givon, 1992; Herbison, 1998), which in turn controls steroid production from the gonad, as well as influencing the activity of $\mathrm{GnRH}$ neurons during suckling (Smith and Grove, 2002). The ARH is also widely regarded as a critical regulator of body weight (for review, see Sawchenko, 1988; Cone et al., 2001; Zigman and Elmquist, 2003), and it has been assumed to serve this role during neonatal life when growth and metabolic activity are so important.

The overall pattern of projections from neurons in the ARH supports the notion that this nucleus represents a nodal point in neural pathways that regulate food intake (Qiu et al., 2001). The ARH provides strong inputs to the $\mathrm{PVH}$ and the $\mathrm{DMH}$ (Sawchenko, 1988; Thompson and Swanson, 2003), and it also sends direct projections to the LHA (Elias et al., 1999), and each of these regions clearly play central roles in regulating ingestive behavior (Sawchenko, 1988; Elmquist et al., 1999). An extensive body of evidence indicates that many of the biological effects of leptin are likely to involve these projection pathways (Sawchenko, 1988; Cone et al., 2001; Zigman and Elmquist, 2003). Injection of retrograde tracers into the PVH or the LHA labeled neurons in the ARH that were doubly labeled for Fos induced by intravenous injections of leptin (Elmquist et al., 1998b; Elias et al., 1999), demonstrating that neurons in both the PVH and the LHA receive leptin-related viscerosensory information from the ARH. Neurons with leptin-induced Fos expression were also found in the posterior part of the $\mathrm{DMH}$, a part of the $\mathrm{DMH}$ that receives high density of inputs from the ARH (Qiu et al., 2001). Furthermore, it has been shown that the ability of leptin to regulate TRH gene expression in the PVH requires intact ARH projection pathways (Legradi et al., 1998; Fekete et al., 2000). Although the peptidergic identity of ARH projections has not been established during the neonatal period, neuropeptide $\mathrm{Y}$ (NPY), agouti-related protein (AgRP), and POMC are expressed in these projections in adult rats and mice (Baker and Herkenham, 1995; Qiu et al., 2001). AgRP neurons appear to be limited to the ARH in adult rodents and terminals containing this neuropeptide were found in the $\mathrm{DMH}, \mathrm{PVH}$, and LHA of neonatal rats in a pattern that coincides with the innervation of ARH axons (Broberger et al., 1998; Bagnol et al., 1999; Grove et al., 2003).

Although the characterization of the ARH pathways regulating feeding is well established in the adult, relatively little is known about the assembly of these circuits during development. The present study reveals that ARH projection pathways are not present at birth, but that they develop entirely postnatally. Moreover, these projections are not mature until the third week of life when pups begin to leave the microenvironment of the nest and search for solid food. Although it is possible that DiI labeling may have underrepresented ARH projections in the newborn mice, this is unlikely because DiI tends to label axons better in younger animals, and we did not see more extensive fiber distributions in cases with larger tracer implants.

The neonatal period is a critical stage of development, during which animals need to maximize caloric intake and maintain appropriate metabolic responses to ensure growth and survival. In light of this need for homeostatic regulation, the immaturity of ARH pathways seems to contraindicate a role for the ARH in relaying leptin signals to other parts of the hypothalamus in neonatal animals. Consistent with this hypothesis, recent studies indicate that leptin does not exert its anorectic effect until the third week of life. Intracerebroventricular, or peripheral, injection of leptin to 9-d-old pups failed to influence milk intake or body weight, whereas by $28 \mathrm{~d}$ of age, administration of leptin inhibited food intake (Mistry et al., 1999; Proulx et al., 2002). In addition, neonatal leptin-deficient mice (Lep ${ }^{\mathrm{ob}} / \mathrm{Lep}^{\mathrm{ob}}$ mice) are not overweight, unlike adults (Mistry et al., 1999), but chronic treatment of neonates with exogenous leptin regulates expression of arcuate neuropeptides implicated in energy homeostasis such as POMC and NPY (Proulx et al., 2002). Consistent with a regulatory action of leptin on postnatal arcuate neurons, we found that administration of leptin on P6-P16 induces Fos expression in POMC neurons of the arcuate nucleus. In addition, a previous study has reported that leptin acts to increase SOCS3 mRNA expression in 
the ARH of P10 rats (Proulx et al., 2002). Immaturity of ARH projection pathways before $\mathrm{P} 18$ may, therefore, partially underlie the documented leptin insensitivity during the first weeks of postnatal development.

The sequential innervation of ARH targets in the hypothalamus suggests that leptin signaling may differentially activate neurons in these target nuclei during development. Leptin administration in adult rodents induces Fos in a limited number of hypothalamic sites with particularly dense increases in Fosimmunoreactive nuclei in the ARH, DMH, PVH, and LHA (Elmquist et al., 1997, 1998b). Changes in Fos staining are generally taken to represent an increase in neuronal activity that can be conveyed either directly by leptin, or through transynaptic activation (Morgan and Curran, 1991; Armstrong and Montminy, 1993). In the present study leptin caused a significant induction of Fos in the ARH as early as P6, whereas leptin-induced Fos induction was not observed in the PVH before P10, nor in the LHA before P16. Taken together with our DiI data, these results indicate that development of leptin-induced c-Fos in the PVH and LHA coincides with innervation of these nuclei by ARH axons. However, we consistently observed Fos staining in the DMH at all ages, but the number and intensity increased after innervation of the DMH by the ARH, suggesting that DMH neurons are both directly and transynaptically regulated by leptin.

The anatomical studies described here revealed two major aspects of ARH development that may also apply to the ontogeny of projections from other hypothalamic nuclei. First, despite the fact that multiple aspects of neuroendocrine physiology are regulated by the hypothalamus at birth, projections from the ARH do not achieve their mature distribution until the third week of life. The ontogeny of ARH projections contrasts with that of afferents to the paraventricular nucleus from the brainstem, which are present at birth (Rinaman, 2001). Similarly, the neurohypophyseal pathway from the PVH, and projections from GnRH neurons, to the median eminence appear to be primarily formed by birth (Daikoku et al., 1984; Wu et al., 1997). Magnocellular neurons also appear to establish their projections to the posterior pituitary before birth. The development of ARH projections contrasts with these neuroendocrine pathways and follows what appears to be an entirely postnatal and sequential pattern of development, with ARH neurons innervating each major target nucleus during a discrete temporal domain. Second, we found no evidence for regressive events playing a role in determining the mature pattern of ARH projections. Thus, the ARH does not appear to provide exuberant projections to inappropriate targets that are then restricted through axon retraction later in development. Rather, the ARH axons appear to achieve their targets though a directed mechanism. Axons extend primarily rostrally out from the ARH through the periventricular zone during the first postnatal week and pass laterally to innervate the $\mathrm{DMH}$, $\mathrm{PVH}$, and LHA in succession. Whether target derived factors are responsible for defining this pattern of innervation remains to be determined, but it is clear that ARH axons are confined to the periventricular zone of the hypothalamus during postnatal development. Similar guidance mechanisms may also act on axons extending from other periventricular nuclei, such as the PVH and AVPV, because each of these nuclei also display primarily periventricular patterns of projections (Swanson and Sawchenko, 1983; Gu and Simerly, 1997).

\section{References}

Armstrong RC, Montminy MR (1993) Transsynaptic control of gene expression. Annu Rev Neurosci 16:17-29.
Bagnol D, Lu X, Kaelin C, Day H, Ollmann M, Gantz I, Akil H, Barsh G, Watson S (1999) Anatomy of an endogenous antagonist: relationship between Agouti-related protein and proopiomelanocortin in brain. J Neurosci 19:RC26.

Baker R, Herkenham M (1995) Arcuate nucleus neurons that project to the hypothalamic paraventricular nucleus: neuropeptidergic identity and consequences of adrenalectomy on mRNA levels in the rat. J Comp Neurol 358:518-530.

Bergen H, Mizuno T, Taylor J, Mobbs C (1998) Hyperphagia and weight gain after gold-thioglucose: relation to hypothalamic neuropeptide $\mathrm{Y}$ and proopiomelanocortin. Endocrinology 139:4483-4488.

Bouret S, Draper S, Polston E, Simerly R (2001) Ontogeny of projections from the arcuate nucleus of the hypothalamus in mice. Proceedings of the 31st Annual Meeting of the Society for Neuroscience, San Diego, November.

Broberger C, Johansen J, Johansson C, Schalling M, Hokfelt T (1998) The neuropeptide $\mathrm{Y} /$ agouti gene-related protein (AGRP) brain circuitry in normal, anorectic, and monosodium glutamate-treated mice. Proc Natl Acad Sci USA 95:15043-15048.

Choi S, Sparks R, Clay M, Dallman M (1999) Rats with hypothalamic obesity are insensitive to central leptin injections. Endocrinology 140:4426-4433.

Cone RD, Cowley MA, Butler AA, Fan W, Marks DL, Low MJ (2001) The arcuate nucleus as a conduit for diverse signals relevant to energy homeostasis. Int J Obes Relat Metab Disord 25:S63-S67.

Daikoku S, Okamura Y, Kawano H, Tsuruo Y, Maegawa M, Shibasaki T (1984) Immunohistochemical study on the development of CRFcontaining neurons in the hypothalamus of the rat. Cell Tissue Res 238:539-544.

de Vries GJ, Simerly RB (2002) Anatomy, development, and function of sexually dimorphic neural circuits in the mammalian brain. In: Hormones, brain and behavior (Pfaff D, Arnold A, Etgen A, Farhbach S, Rubin R, eds). San Diego: Academic.

Debons A, Siclari E, Das K, Fuhr B (1982) Gold thioglucose-induced hypothalamic damage, hyperphagia, and obesity: dependence on the adrenal gland. Endocrinology 110:2024-2049.

Elias C, Saper C, Maratos-Flier E, Tritos N, Lee C, Kelly J, Tatro J, Hoffman G, Ollmann M, Barsh G, Sakurai T, Yanagisawa M, Elmquist J (1998) Chemically defined projections linking the mediobasal hypothalamus and the lateral hypothalamic area. J Comp Neurol 402:442-459.

Elias CF, Aschkenasi C, Lee C, Kelly J, Ahima RS, Bjorbæk C, Flier JS, Saper CB, Elmquist JK (1999) Leptin differentially regulates NPY and POMC neurons projecting to the lateral hypothalamic area. Neuron 23:775-786.

Elias C, Kelly J, Lee C, Ahima R, Drucker D, Saper C, Elmquist J (2000) Chemical characterization of leptin-activated neurons in the rat brain. J Comp Neurol 423:261-281.

Elmquist J, Bjorbaek C, Ahima R, Flier J, Saper C (1998a) Distributions of leptin receptor mRNA isoforms in the rat brain. J Comp Neurol 395:535-547.

Elmquist JK, Ahima RS, Elias CF, Flier JS, Saper CB (1998b) Leptin activates distinct projections from the dorsomedial and ventromedial hypothalamic nuclei. Proc Natl Acad Sci USA 95:741-746.

Elmquist JK, Elias CF, Saper CB (1999) From lesions to leptin: hypothalamic control of food intake and body weight. Neuron 22:221-232.

Elmquist JK, Ahima RS, Maratos-Flier E, Flier JS, Saper CB (1997) Leptin activates neurons in ventrobasal hypothalamus and brainstem. Endocrinol 138:839-842.

Fekete C, Legradi, Mihaly E, Huang QH, Tatro JB, Rand WM, Emerson CH, Lechan RM (2000) $\alpha$-melanocyte-stimulating hormone is contained in nerve terminals innervating thyrotropin-releasing hormone-synthesizing neurons in the hypothalamic paraventricular nucleus and prevents fasting-induced suppression of prothyrotropin-releasing hormone gene expression. J Neurosci 20:1550-1558.

Gerall AA, Givon L (1992) Early androgen and age-related modifications in female rat production. In: Handbook of behavioral neurobiology (Gerall AA, Moltz H, Ward IL, eds), pp 313-354. New York: Plenum.

Grove KL, Allen S, Grayson BE, Smith MS (2003) Postnatal development of the hypothalamic neuropeptide Y system. Neuroscience 116:393-406.

Gu GB, Simerly RB (1997) Projections of the sexually dimorphic anteroventral periventricular nucleus in the female rat. J Comp Neurol 384:142-164.

Gu G, Cornea A, Simerly RB (2001) Sexual differentiation of projections from the principal nucleus of the bed nuclei of the stria terminalis. J Comp Neurol 460:542-562. 
Herbison A (1998) Multimodal influence of estrogen upon gonadotropinreleasing hormone neurons. Endocr Rev 19:302-330.

Kagotani Y, HashimotoT, Tsuruo Y, Kawano H, Daikoku S, Chihara K (1989) Development of the neuronal system containing neuropeptide $Y$ in the rat hypothalamus. Int J Dev Neurosci 7:359-374.

Khachaturian H, Lewis ME, Alessi NE, Watson SJ (1985) Time of origin of opioid peptide-containing neurons in the rat hypothalamus. J Comp Neurol 236:538-546.

Kowalski T, Ster A, Smith G (1998) Ontogeny of hyperphagia in the Zucker (fa/fa) rat. Am J Physiol 275:R1106-R1109.

Kowalski T, Houpt T, Jahng J, Okada N, Liu S, Chua SJ, Smith G (1999) Neuropeptide $\mathrm{Y}$ overexpression in the preweanling Zucker (fa/fa) rat. Physiol Behav 67:521-525.

Legradi G, Emerson CH, Ahima RS, Rand WM, Flier JS, Lechan RM (1998) Arcuate nucleus ablation prevents fasting-induced suppression of ProTRH mRNA in the hypothalamic paraventricular nucleus. Neuroendocrinology 68:89-97.

Madeira MD, Lieberman AR (1995) Sexual dimorphism in the mammalian limbic system. Prog Neurobiol 45:275-333.

Markakis EA (2002) Development of the neuroendocrine hypothalamus. Front Neuroendocrinol 23:257-291.

Meister B, Ceccatelli S, Hokfelt T, Anden N, Anden M, Theodorsson E (1989) Neurotransmitters, neuropeptides and binding sites in the rat mediobasal hypothalamus: effects of monosodium glutamate (MSG) lesions. Exp Brain Res 76:343-368.

Mistry A, Swick A, Romsos D (1999) Leptin alters metabolic rates before acquisition of its anorectic effect in developing neonatal mice. Am J Physiol 277:R742-747.

Morgan JI, Curran T (1991) Stimulus-transcription coupling in the nervous system: involvement of the inducible proto-oncogenes fos and jun. Annu Rev Neurosci 14:421-451.

Morton GJ, Niswender KD, Rhodes CJ, Myers Jr MG, Blevins JE, Baskin DG, Schwartz MW (2003) Arcuate nucleus-specific leptin receptor gene therapy attenuates the obesity phenotype of Koletsky $(\mathrm{fa}(\mathrm{k}) / \mathrm{fa}(\mathrm{k}))$ rats. Endocrinology 144:2016-2024.

Proulx K, Richard D, Walker C-D (2002) Leptin regulates appetite-related neuropeptides in the hypothalamus of developing rats without affecting food intake. Endocrinology 143:4683-4692.

Qiu K, Colman J, Simerly RB (2001) Efferent connections of the arcuate nucleus of the hypothalamus. Proceedings of the 31st Annual Meeting of the Society for Neuroscience, San Diego, November.
Rinaman L (2001) Postnatal development of catecholamine inputs to the paraventricular nucleus of the hypothalamus in rats. J Comp Neurol 438:411-422.

Sawchenko PE (1988) Toward a new neurobiology of energy balance, appetite, and obesity: the anatomists weigh in. J Comp Neurol 402:435-441.

Sawchenko PE, Swanson LW (1983) The organization of forebrain afferents to the paraventricular and supraoptic nuclei of the rat. J Comp Neurol 218:121-144.

Simerly RB (1998) Organization and regulation of sexually dimorphic neuroendocrine pathways. Behav Brain Res 92:195-203.

Simerly RB (2002) Wired for reproduction: organization and developmentof sexually dimorphic circuits in the mammalian forebrain. Annu Rev Neurosci 25:507-536.

Smith MS, Grove KL (2002) Integration of the regulation of reproductive function and energy balance: lactation as a model. Front Neuroendocrinol 23:225-256.

Swanson LW (1992) Brain maps: structure of the rat brain. Amsterdam: Elsevier Science.

Swanson LW (1987) The hypothalamus. In: Handbook of chemical neuroanatomy, Vol 5, Integrated Systems of the CNS, Part I (Björklund A, Hökfelt T, Swanson LW, eds), pp 1-124. Amsterdam: Elsevier.

Swanson LW, Sawchenko PE (1983) Hypothalamic integration: organization of the paraventricular and supraoptic nuclei. Annu Rev Neurosci 6:269-324.

Thompson RH, Swanson LW (2003) Structural characterization of a hypothalamic visceromotor pattern generator network. Brain Res Brain Res Rev 41:153-202.

Thompson RH, Cantreras NS, Swanson LW (1996) Organization of projections from the dorsomedial nucleus of the hypothalamus: a PHA-L study in the rat. J Comp Neurol 376:143-173.

Tobet SA (2002) Genes controlling hypothalamic development and sexual differentiation. Eur J Neurosci 16:373-376.

Tobet SA, Hanna IK (1997) Ontogeny of sex differences in the mammalian hypothalamus and preoptic area. Cell Mol Neurobiol 17:565-601.

Woods S, Seeley R, Porte D, Schwartz M (1998) Signals that regulate food intake and energy homeostasis. Science 280:1378-1383.

Wu TJ, Gibson MJ, Rogers MC, Silverman AJ (1997) New observations on the development of the gonadotropin-releasing hormone system in the mouse. J Neurobiol 33:983-998.

Zigman JM, Elmquist JK (2003) Minireview: from anorexia to obesity-the yin and yang of body weight control. Endocrinology 144:3749-3756. 